\title{
Arbor
}

\section{La conservación arqueológica}

\author{
Concepción Cirujano Gutiérrez, Ana Laborde Marqueze
}

Arbor CLXIX, 667-668 (Julio-Agosto 2001), 691-709 pp.

Entendemos la conservación arqueológica como la tarea de conservar, en el sentido más amplio del término, los conjuntos arqueológicos, es decir, tanto las estructuras como los materiales asociados a ellas.

Comenzaremos definiendo los conceptos de Patrimonio Histórico y de Patrimonio Arqueológico, en el marco de la legislación vigente, y viendo cómo se refleja la preocupación por la conservación de este tipo de patrimonio en los Convenios Internacionales, en la Ley del Patrimonio Histórico Español y en las Leyes de Patrimonio de las distintas Comunidades Autónomas. Para abordar estas cuestiones nos remitimos al texto de Querol y Martínez La gestión del patrimonio arqueológico en España (1996), que recoge y comenta de forma exhaustiva el estado de la cuestión hasta la fecha de su publicación.

El interés de las personas por la conservación de los restos del pasado comienza a producirse en este siglo, cuando se amplía la educación a todas las capas de la sociedad. En la Ley del Patrimonio Histórico Español se define el término Patrimonio Histórico como el principal testigo de la contribución histórica de los españoles a la civilización universal, que comprende los bienes muebles e inmuebles que lo constituyen, el Patrimonio Arqueológico y el Etnográfico, los $\mathrm{Mu}$ seos, Archivos y Bibliotecas, el Patrimonio Documental y el Bibliográfico. El Patrimonio Arqueológico es, por tanto, una parte específica del mismo, siendo uno de sus signos diferenciales el hecho de que se defina por la posibilidad de ser estudiado con una metodología concreta: la arqueológica ${ }^{1}$.

Es el único tipo de patrimonio que está definido en la normativa legal por su metodología. El artículo 40.1 nos da la definición de Patrimonio Arqueológico: son los bienes muebles o inmuebles de carácter 


\section{Concepción Cirujano Gutiérrez, Ana Laborde Marqueze}

histórico, susceptibles de ser estudiados con metodología arqueológica, hayan sido o no extraidos y tanto si se encuentran en la superficie o en el subsuelo, en el mar territorial o en la plataforma continental, los elementos geológicos y paleontológicos relacionados con la historia del hombre y sus orígenes $y$ antecedentes.

Las leyes publicadas con posterioridad por algunas Comunidades Autónomas han mantenido esta definición con ligeras matizaciones.

La metodología arqueológica se centra en el análisis de los restos materiales de las sociedades del pasado, con el fin de reconstruirlas o representarlas. Estos restos, según la tradición, no deben ser textos escritos traducibles e interpretables, pues si lo son ya no es la Arqueología la ciencia que de ellos se ocupa.

Todo lo que ha salido de las manos del ser humano y que sirve para reconstruir su historia son restos del pasado. Todo por ello, puede y debe ser estudiado con metodología arqueológica si quiere reconstruirse la sociedad o el momento que lo hizo y le dio un contexto funcional.

Estos restos son también bienes de dominio público, que se caracterizan por estar excluidos del tráfico jurídico privado, exclusión que tiene como principal finalidad la de asegurar el uso público de esos bienes, lo que no resulta incompatible con la existencia sobre ellos de una propiedad privada ${ }^{2}$.

El análisis de los textos legales vigentes nos lleva, por tanto, a la conclusión de que no existe una clara frontera que permita separar el patrimonio arqueológico de los otros tipos de patrimonio histórico contemplados en la normativa. Parece evidente que todo bien histórico que está enterrado u oculto y es descubierto por cualquier causa es patrimonio arqueológico y, por tanto, es de dominio público. Pero también sabemos, que la metodología arqueológica puede aplicarse a cualquier elemento o resto del pasado, esté o no enterrado u oculto.

\section{Las Convenciones Internacionales}

Además de la Ley del Patrimonio Histórico Español y de las Leyes de Patrimonio Histórico o Cultural de las Comunidades Autónomas, el patrimonio arqueológico está sometido a otro tipo de normativa con el más alto rango: los Convenios o Convenciones Internacionales, que nuestro país ha suscrito.

La preocupación por la conservación del patrimonio en nuestro siglo arranca con la Carta de Atenas (1931 y 1933), derivada de un Congreso Internacional de Arquitectura sobre Conservación de Monumentos de 
Arte e Historia. Sin carácter obligatorio, tuvo una gran incidencia en la historia de la opinión sobre la conservación y la restauración. En esta carta se legitima, siempre y cuando las condiciones lo permitan, la práctica de la anastilosis o recomposición de los elementos originales encontrados, pero teniendo en cuenta que los nuevos materiales necesarios para este fin deberán ser siempre reconocibles.

Especialmente interesante e importante para España es el inicio en 1986 de la emisión de normas obligatorias de la Comunidad Económica Europea, hoy Unión Europea. Mencionaremos también el papel de la Unesco y del Consejo de Europa, como organismos emisores de normativas diversas.

El primero de los textos que se publican referidos de forma específica al Patrimonio Arqueológico es la Recomendación de la UNESCO sobre los Principios Internacionales que deberán aplicarse a las Excavaciones Arqueológicas (1956). En este texto aparece por primera vez la expresión Patrimonio Arqueológico. Se considera la excavación arqueológica como toda investigación que tenga por finalidad el descubrimiento de objetos de carácter arqueológico, tanto en los casos de excavación del suelo, exploración de la superficie o en el lecho o subsuelo de aguas interiores $y$ territoriales. La gestión preventiva se tiene en cuenta con claridad, recomendando la creación de Servicios de Arqueología en cada demarcación territorial, con una documentación centralizada. Advierte igualmente sobre la conveniencia de conservar intactos cierto número de lugares arqueológicos y de dejar testigos sin tocar en las excavaciones más importantes. Se indica el deber de asegurar el mantenimiento de las excavaciones y de los monumentos, vigilar con atención la restauración de los vestigios y de los objetos y que se prevea la custodia, el mantenimiento y el acondicionamiento de los lugares, de los objetos y de los monumentos.

También se recomienda que se emprenda una acción educativa para despertar y desarrollar el respeto del público por los vestigios del pasado, que exista la obligación de publicar los resultados de las excavaciones o que en los lugares arqueológicos importantes se cree un establecimiento de tipo museo para que el visitante pueda comprenderlos mejor.

La mayoría de estos puntos fueron recogidos posteriormente en el Convenio Europeo para la Protección del Patrimonio Arqueológico (Londres 1969), adoptado por nuestro país como norma en 1975. Aunque pasa bastante inadvertido, muchos de sus principios sirvieron como base para la redacción de la Ley del Patrimonio Histórico Español. Este convenio ha sido revisado con posterioridad, en Malta en 1992. 
En el documento de Malta se sigue hablando de excavaciones o descubrimientos, pero concediéndole una gran importancia al entorno y al contexto de los bienes arqueológicos. La conservación del patrimonio arqueológico excavado adquiere ahora un notable protagonismo. Los conceptos de salvamento o rescate son sustituidos por el de conservación, pasando del culto al objeto al reconocimiento del valor de los contextos. Malta 92 opta por la conservación en el lugar original, siempre que sea posible, y añade un apartado fundamental: ni los restos ni los yacimientos deberán extraerse o dejarse en su lugar sin que se tomen medidas para su conservación y su gestión. Se especifica además, que en el caso de que se decida extraer o desplazar de su lugar de origen los restos arqueológicos, los museos deberán estar acondicionados para su conservación. Se promueve el acceso del gran público a los yacimientos, siempre que las visitas masivas no supongan un riesgo para su mantenimiento.

Se adopta por vez primera el concepto de conservación integral del patrimonio arqueológico, incluida en el ciclo de la investigación arqueológica. "Adquiere importancia no el objeto aislado, museable, desprovisto de su contexto, sino el paisaje, el entorno, el ambiente en el que se sitúa el yacimiento junto con el propio yacimiento, como una dualidad inseparable. Lo que interesa no es el conocimiento científico restringido a la esfera académica, sino la difusión a todos los niveles de la sociedad para conseguir una valoración popular que los bienes arqueológicos nunca han alcanzado» ${ }^{3}$.

Otro documento de interés es la Carta para la Protección y Gestión del Patrimonio Arqueológico de la UNESCO (Lausanne. 1990). Se trata de una iniciativa llevada a cabo por el ICAHM (Comité Internacional para la Gestión del Patrimonio Arqueológico), perteneciente al ICOMOS. Esta carta pretende ser comparable a la firmada en Venecia (1964) respecto al Patrimonio Arquitectónico, ofreciendo una serie de puntos de partida para la identificación, protección, conservación y presentación al público de los restos del pasado. La protección del patrimonio arqueológico debe fundarse en una colaboración efectiva entre especialistas de numerosas disciplinas y los servicios públicos, las empresas y el público en general. Considera el patrimonio arqueológico como la parte de nuestro patrimonio material en la que los métodos de la arqueología suministran los conocimientos básicos, incluyendo todo rastro de la existencia humana, los lugares en los que desarrollaron actividades de cualquier tipo, las estructuras o vestigios abandonados junto con el material asociado. Insiste también en que se trata de una riqueza frágil y no renovable. El control de las intervenciones se considera 


\section{La conservación arqueológica}

necesario, prestando atención a la investigación, la formación profesional y la ética.

Pone gran énfasis en la conservación del yacimiento en su lugar original, con un mantenimiento correcto y la garantía de los medios para ello. Considera que toda excavación supone una destrucción y que se harán por tanto con preferencia en los sitios condenados a desaparecer. Deberá ser, en cualquier caso, lo menos destructiva posible.

La preocupación existente sobre la conservación del patrimonio arqueológico queda reflejada igualmente en la Asamblea General del IC$C R O M$, celebrada en Roma en el año 1983. Se aprueba una resolución en la que se recomienda a los Estados Miembros que tomen las medidas necesarias para impedir que se excaven yacimientos arqueológicos, salvo en circunstancias especiales, cuando no se ha prestado la debida consideración a las exigencias necesarias de conservación.

Mencionaremos también, en el ámbito de la conservación propiamente dicha, la Carta del Restauro de 1987, redactada a partir de la de Venecia de 1964 antes mencionada y de la del Restauro de 1972.

Estas Cartas suponen el establecimiento de una normativa general que debe aplicarse en las intervenciones sobre bienes culturales, a partir de la experiencia del Istituto Centrale del Restauro de Roma, dirigido por Cesare Brandi hasta 1960. En 1972 se planteaba ya la exigencia de reversibilidad de toda operación restauradora y se intentaba armonizar la estética de la obra con su historia material, de la manera más equilibrada posible, tal y como defiende la teoría brandiana. La ayuda de otras ciencias se consideraba indispensable y se admitía el uso de nuevos materiales (resinas) con fines estáticos y cuando los tradicionales se mostraran insuficientes. Se refiere fundamentalmente a los bienes muebles.

En la Carta de 1987 se concede gran atención a las obras de interés arquitectónico, que en la Carta del 72 se trataban con el mismo concepto que los bienes muebles, predominando los aspectos visuales sobre la estructura.

Destaca la puesta de valor de las técnicas y materiales tradicionales frente a los modernos, cuyo uso desde la Carta de Atenas, venía recomendándose para funciones de estática y consolidación estructural, habiendo sido utilizados para la restauración de forma generalizada y que habían dado bastantes problemas de envejecimiento y reversibilidad (deterioro de las restauraciones en el Partenón con cemento armado, frente a los buenos resultados del travertino empleado en el Arco de Tito y el ladrillo del Coliseo). Existe ahora una mayor permisividad hacia las reintegraciones de imagen en el ámbito de la ar- 
quitectura, siempre que sean reconocibles y se justifiquen por razones de asegurar la conservación de la obra.

En cualquier caso, se rechazan las adiciones de estilo o analógicas, incluso en formas simplificadas, aunque estén documentadas. Tan sólo se admitirán reducidas a lo esencial y siempre que estén justificadas por razones de conservación. Es lo que entendemos por sólido capaz.

En esta Carta se definen claramente los términos: conservación, prevención, salvaguardia, restauración y mantenimiento:

* Conservación, es el conjunto de actuaciones de prevención y salvaguardia referidas a asegurar una duración pretendidamente ilimitada a la configuración material del objeto considerado. Refiriéndose también a las condiciones del contexto ambiental.

* Prevención, es el conjunto de actuaciones de conservación, motivadas por conocimientos predictivos al más largo plazo posible, sobre el objeto considerado y sobre las condiciones de su contexto ambiental.

* Salvaguardia, es cualquier medida de conservación y preservación que no implique intervenciones indirectas sobre el objeto considerado.

* Restauración, es cualquier intervención que, respetando los principios de la conservación, y sobre la base de todo tipo de indagaciones cognoscitivas previas, se dirija a restituir al objeto, en los límites de lo posible, la relativa legibilidad y, donde sea posible, el uso.

* Mantenimiento, es el conjunto de actuaciones encaminadas a mantener los objetos de interés cultural en condiciones óptimas de integridad y funcionalidad, especialmente después de que hayan sufrido intervenciones excepcionales de conservación y/o de restauración.

Lo que entendemos por Conservación Preventiva englobaría estas labores de mantenimiento, así como las actuaciones llevadas a cabo sobre el contexto medioambiental, ralentizando los procesos de deterioro.

Se entiende que Conservación y Restauración son acciones complementarias y un programa de restauración nunca podrá prescindir de un adecuado programa de salvaguardia, mantenimiento y prevención.

\section{La Legislación Española}

Dejando aparte el campo internacional, la Administración General del Estado se compromete después de publicada la Constitución, a redactar una nueva Ley: es la Ley del Patrimonio Histórico Español de 1985, que constituye el marco legal más amplio para el tratamiento 
de los bienes culturales de nuestro país y cuyos objetivos fundamentales son la protección, el acrecentamiento y la transmisión del patrimonio histórico español a las generaciones futuras. Al año siguiente, se publica el Real Decreto de Desarrollo parcial 111/1986 modificado en 1994, y después el Reglamento de Museos, al que han sucedido otros.

En la Ley 16/85 de Patrimonio Histórico Español (LPHE) se introduce un nuevo concepto de Patrimonio Histórico, ampliando su contenido a materiales que no tienen por qué considerarse artísticos ni tampoco valiosos en el sentido crematístico del término. Integra también, por primera vez en la legislación española, bienes no físicos, como danzas, músicas o costumbres.

Defiende la protección de todos esos bienes por encima de cualquier factor jurídico al que estén sometidos, es decir con independencia del carácter de la propiedad: bienes de la iglesia, de particulares, de propiedad pública, los contenidos en un museo e incluso los que no hayan sido aún descubiertos.

Establece tres categorías para los bienes muebles y dos para los inmuebles, que se corresponden con diferentes grados de protección. El máximo nivel es el de Bien de Interés Cultural (B.I.C.), que exige una declaración y la inclusión en el Registro de Bienes de Interés Cultural. El grado medio, que sólo afecta a los muebles, necesita también una declaración y para ello se crea el Inventario General de Bienes Muebles. El tercer nivel se aplica a los bienes integrantes del patrimonio histórico, por el simple hecho de serlo, y el mecanismo de protección básico para ellos es la elaboración de los Planes Nacionales de Información.

Define y trata cuatro tipos de patrimonio especiales, entre ellos el Arqueológico, que pude ser tanto mueble como inmueble.

Elabora una tipología de bienes inmuebles que pueden ser declarados de interés cultural: Monumentos, Jardines, Conjuntos y Sitios Históricos y Zonas Arqueológicas. No sólo incluye limitaciones y prohibiciones, sino que busca cauces a través de medidas tributarias y fiscales, para estimular la conservación y el acrecentamiento del Patrimonio Histórico.

En el tema de la Conservación se establece el compromiso de procurar que la técnica más moderna respalde la conservación, consolidación y mejora. En la difícil decisión histórica sobre la naturaleza destructiva o no de las restauraciones, esta ley adopta una posición conservadora y algo idealista: sólo de manera excepcional se eliminará alguna de las aportaciones de las diferentes épocas propias del bien y si resulta necesario hacerlo, se documentará de la forma debida. En el caso de 


\section{Concepción Cirujano Gutiérrez, Ana Laborde Marqueze}

los inmuebles, se evitarán los intentos de reconstrucción mimética, salvo cuando se utilicen partes originales de los mismos y pueda probarse su autenticidad. Si se añadiesen materiales o partes indispensables para su estabilidad o mantenimiento, las adiciones deberán ser claramente reconocibles. Los B.I.C. no podrán ser sometidos a tratamiento alguno, sin autorización expresa de los organismos competentes para la ejecución de la ley (Art. 39).

En cualquier caso, «se echa en falta la existencia de un Reglamento General de Intervenciones en los Bienes del Patrimonio Histórico, así como otro específico referido al Patrimonio Arqueológico. Se han producido numerosas impugnaciones realizadas por algunas Comunidades Autónomas, a raíz de la publicación de la ley, lo que demuestra que se hizo sin un análisis profundo de los estatutos de transferencias y demostrando también que la coordinación entre las distintas administraciones resulta imprescindible. Si no existe una cooperación muy fluida, es difícil conseguir una imagen global del patrimonio histórico que permita evaluar de forma equilibrada las razones de su destrucción, sus necesidades de conservación y los medios para su difusión» ${ }^{4}$.

La LPHE adolece quizás de un planteamiento más integral del patrimonio histórico, una visión más global de los bienes, independientemente de su naturaleza o su significado, que nos permita centrar la atención no sólo en los Tipos de Patrimonio, sino en los Tipos de Intervención que sobre él pueden llevarse a cabo, y que deberían estar perfectamente definidas y reglamentadas, facilitando así su protección y conservación.

En el año 1985. se crea el I.C.R.B.C (Instituto de Conservación y Restauración de Bienes Culturales, ahora Instituto del Patrimonio Histórico Español I.P.H.E) como un proyecto innovador, ambicioso y bien planteado, que superaba el tratamiento parcial del patrimonio histórico, adaptándose a un modelo administrativo con unas funciones nuevas y distintas. Se convirtió así en un centro pionero y especializado en la investigación sobre conservación y restauración, capaz de ofrecer apoyo técnico a otras instituciones u organismos.

A iniciativa de este centro, y dentro del ámbito de sus atribuciones, se redacta en el año 1990 un documento que intenta una reglamentación básica de las intervenciones en los bienes del patrimonio histórico, considerados de forma global e independientemente de su naturaleza. Y que se proponía, en principio, elaborar un reglamento parcial de la Ley del Patrimonio Histórico Español, referente a las intervenciones en el patrimonio arqueológico. 


\section{La conservación arqueológica}

Sin embargo, debido a la dificultad de reglamentar por separado este tipo de patrimonio, se planteó la necesidad de ampliar el ámbito de trabajo, a la totalidad de las intervenciones en el patrimonio histórico.

\section{Las Comunidades Autónomas}

En lo referente a las Comunidades Autónomas, las aportaciones no son muy significativas en cuanto a reglamentación y protección del patrimonio arqueológico.

Destacaremos que en la Ley del Patrimonio Histórico de Castilla La Mancha (1990) el concepto de bien cultural se amplía con la introducción de la Arqueología Industrial y la ampliación del ámbito de la Etnografía. En cuanto al grado de protección de los bienes, conserva la figura máxima de B.I.C., con la misma tipología que la estatal, introduciendo la de Parque Arqueológico. Entre sus aportaciones destaca el tratamiento del entorno.

En la Ley del Patrimonio Histórico Andaluz (1991), con un desarrollo reglamentario casi completo, se intenta potenciar la intervención preventiva y se introduce la figura de zona de servidumbre arqueológica, en la que se exige que el planteamiento urbanístico tenga en cuenta la posible existencia de restos arqueológicos.

Crea la figura de Conjunto Arqueológico, con la finalidad de facilitar la administración y la custodia de yacimientos arqueológicos de características relevantes o especiales. En las actuaciones de conservación destaca la necesidad de un proyecto previo y un informe posterior para cualquiera de ellas. El proyecto, que irá suscrito por personal técnico competente, se ajustará a un reglamento y deberá incluir como mínimo la identificación del bien, la diagnosis, las propuestas de actuaciones tanto teóricas como técnicas y económicas y la descripción de la metodología a emplear. El visado corresponde siempre a la Consejería de Cultura.

En esta Comunidad se creó en 1989 el Instituto Andaluz de Patrimonio Histórico, con la finalidad de promover las actividades científicas y de desarrollo tecnológico establecidas en el plan andaluz de investigación en materia de patrimonio histórico. Además de ello desarrolla actividades relacionadas con la formación de profesionales y la sistematización de documentación.

Este organismo ha puesto en marcha un Programa de normalización de estudios previos y control de calidad en las intervenciones, tanto sobre bienes de carácter mueble como inmueble, orientado a que los proyectos 
de intervención se basen en una serie de conocimientos previos sobre el bien a restaurar y que la intervención se efectúe con unas mínimas garantías de calidad, tanto de los materiales como de las técnicas.

En la Ley del Patrimonio Cultural Catalán (1993) se amplía el concepto de patrimonio cultural, dividiéndolo en bienes muebles, inmuebles e inmateriales e incluyendo las manifestaciones de la cultura tradicional y popular. Introduce los Espacios de Protección Arqueológica, figura creada especialmente para el patrimonio arqueológico no conocido.

Las intervenciones en monumentos, jardines, zonas arqueológicas o zonas paleontológicas, deberán estar autorizadas por el Departamento de Cultura. Cualquier proyecto de intervención sobre un Bien de Interés Nacional Inmueble incluirá un informe sobre sus valores históricos, artísticos y arqueológicos, sobre su estado de conservación y la evaluación del impacto de tal intervención. Se establecen, asimismo, una serie de criterios de intervención para determinadas figuras de máxima protección, entre ellas para las Zonas Arqueológicas, desde el respeto por sus valores hasta la prohibición de colocar publicidad en ellas, de reconstruir o de eliminar partes.

Mención aparte merece el Centro de Arqueología Subacuática de Cataluña (C.A.S.C.), con funciones técnicas de inventario, protección, conservación, estudio y difusión del patrimonio arqueológico que se encuentra sumergido en aguas costeras e interiores.

En la Ley del Patrimonio Cultural de Galicia (1995) destaca el tratamiento dado al tema del impacto ambiental, más desarrollado que en cualquiera de los otros textos.

Las intervenciones sobre los B.I.C. deberán estar debidamente autorizadas y en los proyectos de intervención habrá de incorporarse un informe sobre su importancia artística, histórica o arqueológica, elaborado por personal técnico competente en cada una de estas materias. Una vez terminada la intervención, se realizará una memoria con la descripción de la obra ejecutada y de los tratamientos aplicados, junto con la documentación gráfica del proceso. Las intervenciones irán siempre encaminadas a la conservación y mejora, respetando las características esenciales del bien y las contribuciones de las distintas épocas. Se evitarán los intentos de reconstrucción y no podrán realizarse adiciones miméticas ni acciones agresivas.

Se crea el Instituto de Conservación y Restauración de Bienes Culturales de Galicia, con un servicio de arqueología, que se encarga de programar, coordinar y ejecutar las intervenciones en el patrimonio arqueológico. 
La protección del patrimonio arqueológico tiene especial relevancia en la Ley del Patrimonio Cultural Valenciano (1998), que establece varias figuras.

Por un lado las Zonas Arqueológicas, como Bienes de Interés Cultural de tipo inmueble, cuya declaración requiere un estudio previo, planes especiales y protección integral. En ellas se podrán delimitar Áreas de Reserva, destinadas a investigaciones futuras.

Por otro lado se definen también los espacios y las áreas de protección arqueológica para los lugares donde se sospeche la existencia de restos y las áreas en las que se presuma la existencia de restos arqueológicos o áreas de sospecha.

La Ley de Patrimonio Histórico de la Comunidad de Madrid (1998) asume explícitamente que la conservación del patrimonio es una tarea inexcusable para la pervivencia de la memoria colectiva y se anuncia la creación de un Instituto de Conservación y Restauración de Bienes Culturales. Establece igualmente tres grados de protección de los bienes. La figura arqueológica de máxima protección vuelve a ser la Zona Arqueológica, existiendo en esta Comunidad un buen número de ellas.

En la mayor parte de las Comunidades Autónomas se cuenta con Comisiones o Consejos específicos para el Patrimonio Arqueológico, encargados de asesorar, informar y proponer cuantas medidas se consideren necesarias para la protección, conservación e investigación del patrimonio arqueológico de la comunidad correspondiente. Participan en la programación anual de actividades arqueológicas, en la conservación de cuevas y abrigos con arte rupestre, proponen la declaración de yacimientos arqueológicos como bienes de interés cultural y colaboran en la elaboración del Inventario del Patrimonio Cultural.

A la vista de lo anteriormente expuesto, podemos concluir que la cobertura legislativa del patrimonio arqueológico es desigual en las distintas Comunidades Autónomas. No se contemplan las intervenciones de forma integral, ni se exige una metodología de intervención con unos criterios mínimos de calidad, ni se garantiza la conservación de los restos extraídos, ni tampoco se regula la exigencia de titulaciones a los técnicos implicados en los proyectos.

\section{Mecanismos de alteración}

Los materiales y conjuntos arqueológicos se ven sometidos a una serie de mecanismos de deterioro debidos a las características del se- 
dimento en que permanecen, pero sobre todo, al brusco cambio que padecen en el momento de la excavación.

El suelo es un compuesto mineral y orgánico que puede presentar características muy diversas. Se deberán considerar, por tanto, una serie de factores físicos, químicos y biológicos, que al actuar de manera combinada condicionarán el estado de conservación de los depósitos arqueológicos.

El agua, en sus distintos estados tiene una gran importancia. Los suelos impermeables permiten unas mejores condiciones de conservación; por el contrario los más permeables favorecen la circulación del agua y los niveles elevados de humedad, provocando la degradación de los materiales orgánicos y la hidrólisis, disolución y erosión de los inorgánicos. Cuando el sistema poroso de estos materiales llega a la saturación total, alcanza un grado de extrema fragilidad debido a un proceso de hidrólisis extensiva, pero si las condiciones son anaerobias (con ausencia de oxígeno), se llega a un perfecto equilibrio con el medio.

Por otro lado, el agua puede llevar en su composición un mayor o menor porcentaje en sales solubles cuya influencia en el deterioro depende de la frecuencia de los ciclos de humedad-sequedad. Por tanto, los ciclos sucesivos de solubilización y cristalización de las sales, pueden dar lugar a continuas tensiones en la estructura interna de los materiales.

Otro de los factores que influye en la conservación es el ph del suelo, que está directamente relacionado con la escasa presencia de bases, el contenido en sílice y la incompleta descomposición de la materia orgánica.

Es fundamental también el contenido en materia orgánica y la acción de las bacterias, que juegan un papel decisivo en la degradación de los objetos.

El equilibrio en que pudieran encontrarse los objetos se rompe en el momento de la extracción, pasando a unas condiciones de humedad y temperatura totalmente diferentes a las que se hallaban, y quedando además expuestos a la acción de las radiaciones solares. Los objetos orgánicos son especialmente sensibles a estos cambios y, por tanto, es sumamente importante protegerlos y embalarlos adecuadamente con el fin de minimizar los riesgos.

Los restos que permanecen en el yacimiento deberán protegerse con estructuras más o menos complejas. En la mayor parte de los casos, se trata de conservar vestigios arquitectónicos exentos o incompletos, que por tanto carecen de protección, siendo más vulnerables 
a la acción de factores medioambientales y antrópicos. Además de ello, deberán arbitrarse las labores de mantenimiento y control necesarias para lograr una adecuada conservación de los conjuntos.

\section{Metodología de las actuaciones}

Los trabajos de conservación en general y cualquier tipo de intervención sobre los bienes culturales tanto muebles como inmuebles, posibilitan el acercamiento a la obra y un estudio profundo del material, su problemática, la técnica de ejecución o manufacturación e incluso un conocimiento del contexto o medio en el que han permanecido.

A la hora de plantearnos una actuación de conservación estaremos buscando, en primer lugar, la permanencia de esos bienes culturales. Y podemos ir aún más lejos, afirmando que un bien cultural no estará plenamente reconocido mientras no exista una preocupación por su conservación.

Ahora bien, los medios empleados nunca deberán afectar a la naturaleza de esos bienes, ni a sus materiales constitutivos, ni a su significado, respetando siempre la integridad de los mismos. Hay que ser conscientes de que la intervención puede conllevar la eliminación de parte de la historia material del bien cultural, pero también facilita su comprensión y por tanto favorece su accesibilidad. Es necesario, por todo ello, buscar un equilibrio a la hora de plantear las actuaciones.

La conservación supone por tanto, una toma de conciencia de la materialidad de las obras o conjuntos, entendiendo que la materia no es la simple expresión de su autenticidad, sino que está en su estructura, en su composición físico-química, en la información que encierran.

Para asegurar esa permanencia y esa integridad es necesario estabilizar los procesos de deterioro. Es por ello sumamente importante llegar a comprender los mecanismos de alteración que han afectado al estado de conservación de los materiales arqueológicos, de las estructuras y de los restos encontrados, en relación con las características del suelo, con la propia naturaleza de los materiales constitutivos y con las condiciones de humedad, temperatura e iluminación, es decir con los factores medioambientales. Este conocimiento previo nos facilitará la posterior intervención sobre los mismos.

Lograr estos objetivos no es una tarea sencilla y no se limita, como tratamos de explicar, a la simple restauración de la obra o de los conjuntos, es decir a intervenir sobre su materialidad. Requiere una 


\section{Concepción Cirujano Gutiérrez, Ana Laborde Marqueze}

serie de trabajos amplios y complejos y para ello es necesario involucrar a especialistas de diferentes áreas. Al igual que en la investigación arqueológica propiamente dicha, además de arqueólogos o prehistoriadores, participan paleontólogos, geólogos, biólogos,.... Para la conservación de los bienes culturales, deberemos contar con historiadores del arte, arqueólogos, prehistoriadores, arquitectos, físicos, químicos, biólogos, geólogos, ... Cada uno aportará sus conocimientos a la hora de planificar y proyectar una intervención adecuada, que contemple tanto los objetos como el contexto. Es lo que entendemos por equipos interdisciplinares.

La colaboración entre los distintos especialistas deberá ser permanente en todo el proceso y el diálogo siempre fluido. Relación de diálogo y de respeto mutuo, buscando siempre el equilibrio entre las prioridades del investigador y del conservador. No siempre contamos con los medios económicos necesarios para integrar todo tipo de estudios previos y técnicos en los proyectos, pero hemos de ser muy cautelosos con las limitaciones de cada uno y saber hasta dónde podemos llegar en cada momento. Que existan tareas que todos podamos realizar con una simple asesoría o unos mínimos de información no quiere decir que podamos resolver todas las situaciones. Es importante conocer las posibilidades de las otras ciencias auxiliares. Toda prudencia y reflexión es poca antes de la actuación, debido al potencial de información que se puede perder.

La conservación de los restos y del material arqueológico se ha planteado tradicionalmente como un trabajo excepcional, cuando «sobra presupuesto» y que se «apaña» con la colaboración de los más «manitas». Pero en la actualidad, al existir cada vez más restauradores en los museos y al formar parte de los ciclos de formación la Conservación del Patrimonio, los arqueólogos y prehistoriadores van tomando conciencia de la importancia de las condiciones de extracción de los restos, - para no perder esa información contenida en ellos y para minimizar su posterior tratamiento-, y de la relevancia que tiene la presencia de un técnico «in situ», cuando las condiciones lo requieran. Lo mismo ocurre con los lugares arqueológicos, en la medida en que vamos siendo conscientes de la destrucción que supone no conservar los vestigios extraídos.

En los últimos tiempos, se ha producido un aumento enorme de los hallazgos a conservar y de los sitios excavados, así como del número de visitantes de los lugares arqueológicos. Estos hechos nos llevan de nuevo a insistir sobre la importancia de la planificación para la acción de la conservación y la búsqueda de un equilibrio entre ambos términos conservación y excavación. 


\section{La conservación arqueológica}

Las intervenciones serán siempre las mínimas y se realizarán de forma que sean inocuas y reversibles, con productos y materiales garantizados y previamente testados.

Un caso especial lo constituyen los yacimientos musealizados, los eco-museos, los parajes histórico-arqueológicos y los parques culturales o arqueológicos, dentro de un nuevo contexto de rentabilización del Patrimonio Arqueológico, incrementando la función social del mismo. En estos casos, en los que la intervención requiere de un proyecto amplio y complejo, y por supuesto interdisciplinar, se llega hasta la completa rehabilitación de los conjuntos. Las intervenciones serán igualmente reversibles, empleando materiales diferentes de los originales, respetando los vestigios de anteriores actuaciones, cuando no supongan un riesgo para la conservación y siempre con una sólida base documental. Las adiciones nuevas serán siempre reconocibles y estarán justificadas por razones de conservación o legibilidad.

\section{Notas}

1 Querol, M.A.; Martínez, B. La Gestión del Patrimonio Arqueológico en España. Alianza Editorial 1996.

2 QueROL, MARTÍNEZ; La Gestión...

3 QUeROL, MARTÍNEZ; La Gestión...

4 QUeROL, MARTÍNEZ; La Gestión...

\section{Bibliografía}

Agullera Corredera, F.; Ramón Rendón, J.; Valverde Cuevas, F. (1996) Régimen jurídico del patrimonio histórico en Andalucía Consejería de Cultura. Sevilla.

Alegre Ấvila, J.M. (1994) Evolución y régimen jurídico del Patrimonio Histórico Colección Análisis y Documentos $\mathrm{n}^{\circ} 5$. Ministerio de Cultura. Madrid.

Alonso IbÁñez, M.R. (1992) El Patrimonio Histórico: destino público y valor cultural

Ed. Civitas. Madrid.

Barrero Rodriguez, C. (1990) La ordenación jurídica del Patrimonio Histórico Instituto García Oviedo. Universidad de Sevilla. Ed. Civitas. Sevilla.

Benttez de Lugo y Gullé́n, F. (1995) El patrimonio cultural español: aspectos jurídicos, administrativos y fiscales, incentivos en la Ley de Fundaciones Ed. Comares. Granada.

Berducou, M.C. (1990) La conservatiion en archéologie. Méthodes et pratique de la conservation-restauration des vestiges archéologiques Ed. Masson. Paris.

Burgos Estrada, J.C. (1996) La conservación de los bienes culturales en las leyes autonómicas del Patrimonio XI Congreso de Conservación y Restauración de Bienes Culturales. Castellón de la Plana. Diputación de Castellón. 
CAMPS, C.; MARTi, J. (1997) La arqueología en la legislación valenciana sobre patrimonio histórico: algunas reflexiones a propósito de una futura ley autonómica Col.legi de Doctors i Llicenciats en Filosofí ai Lletres i en Ciencies de Valencia i Castelló. Valencia.

Casa Martinez, C. de la et al. (1998) La Ley del Patrimonio Histórico Español en Castilla y León Complutum $\mathrm{n}^{\circ}$ 9. Servicio de Publicaciones. Universidad Complutense. Madrid.

CRonyn, J.M. (1990) The elements of Archaeological Conservation Ed. Routledge. London.

Esbert, R.M.; ORdaz, J.; Alonso, F.J.; Montoto, M. (1997) Manual de diagnosis y tratamiento de materiales pétreos y cerámicos Col.legi dAparelladors i Arquitectes Tècnics de Barcelona..

Escudero, C.; Rosselló, M. (1988) Conservación de materiales en excavaciones arqueológicas Museo Arqueológico de Valladolid.

Galaz Villasante, M. (1995) Algunas observaciones sobre la gestión del patrimonio arqueológico en la actualidad Asociación Española de Museólogos. Revista de Museología.

Garcta Fernández, J. (1987) Legislación sobre Patrimonio Histórico Ed. Tecnos. Madrid.

García Escudero, P.; PendÁs García, B. (1986) El nuevo régimen jurídico del Patrimonio Histórico Español Cultura y Comunicación. Ministerio de Cultura. Madrid.

González Moreno-Navarro, A. (1999) La restauración objetiva (método SCCM de restauración monumental) Memoria SPAl 1993-1998 1 y 2. Diputació de Barcelona. Àrea de Cooperació. Servei del Patrimoni Arquitectònic Local. Barcelona.

I.C.C.R.O.M. (1986) Preventive measures during excavation and site protection Rome.

I.C.C.R.O.M. (1987) 5th. International meeting of experts on the conservation of earthen architecture Rome.

Instituto Andaluz del Patrimono HistóRico(1996) Bases para una carta sobre patrimonio y desarrollo en Andalucía I.A.P.H. Sevilla.

Istituto Poligrafico E ZecCa di Stato (1995) Convention européenne pour la protection du patrimoine archéologique Roma.

Llei del Patrimoni Históric de les Illes Balears (1999) Govern Balear. Consellería d'Educació, Cultura i Esports. Palma de Mallorca.

Ley de Patrimonio de Euskadi (1989) Parlamento Vasco. Vitoria.

Ley de Patrimonio Histórico de la Comunidadde Madrid (1998) Colegio Oficial de Arquitectos. Madrid.

LÓPEZ JAÉn, J. (1998) Conjuntos históricos y entornos monumentales. Normativa y recomendaciones internacionales. Estado de la cuestión. Curso : Documento, espacio y entorno. Coordinado por: Concha Fontenla San Juan. Xunta de Galicia. Consellería de Cultura.

Martin Bueno, M. (1990) La defensa del patrimonio arqueológico en Aragón Institución Fernando el Católico. Zaragoza.

Martínez Justicia, M.J. Carta del Restauro 1987 Colegio de Arquitectos de Málaga.

Meńndez i PaBLo, F.X. (1997) La llei de patrimoni cultural de Catalunya Col.legi de Doctors i Llicenciats en Filosofí ai Lletres i en Ciencies de Valencia i Castelló. Valencia.

Ministerio de Educación y Cultura (1998) Normativa sobre el Patrimonio Histórico Cultural Colección Análisis y Documentos $n^{\circ} 13$. Madrid. 
Moreno de BarReda, F. (1999) Textos fundamentales del Consejo de Europa en materia de Patrimonio Cultural Fundación Hispania Nostra. Madrid.

ontiveros Ortega, E.; Alcalde Moreno, M.; Sebastián Pardo, E. (1996) Programa de normalización de estudios previos y control de calidad en las intervenciones Boletín del Instituto Andaluz del Patrimonio Histórico, año IV. Sevilla.

OrTiz Risco, F. (1994) Arqueología y conservación de yacimientos prehistóricos Boletín del Instituto Andaluz del Patrimonio Histórico, año II, $\mathrm{n}^{\circ}$ 9. Sevilla.

Pérez de Armiñán y de LA Serna, A. (1997) Las competencias del estado sobre el Patrimonio Histórico Español en la Constitución de 1978 Ed. Civitas. Madrid.

Palma, GIovanNa DE (1996) Problemas de conservación y metodología de intervención en los materiales arqueológicos de excavación y museográficos en La Conservación del Patrimonio en el Mundo Mediterráneo. I Encuentro: Criterios de Intervención. Diputació de Castelló.

Poveda SÁNCHEZ, V. (1999) El Patrimonio cultural español: derechos y obligaciones ante su conservación Actas del III Seminario Internacional de la Conferencia de Ciudades Históricas del Mediterráneo. Generalitat Valenciana. Valencia.

Querol Fernández, M.A.; Martinez Díaz, B. (1996) La gestión del Patrimonio Arqueológico en España Alianza Editorial. Madrid.

QuerolFernández,M.A.; MartínezDiaz, B. (1998) El tratamiento de los Bicnes Arqueológicos *en las Leyes de Patrimonio de Valencia y Madrid Complutum no 9. Servicio de Publicaciones. Editorial Complutense. Madrid.

Querol Fernández, M.A.; Martínez Diaz, B. (1998) Modelo y realidad: el patrimonio arqueológico en las Comunidades Autónomas Actas de los VIII Cursos Monográficos sobre el Patrimonio Histórico. Universidad de Cantabria. Ayuntamiento de Reinosa. Santander.

San Martín Montilla, C. (1994) La protección del patrimonio arqueológico desde el museo, criterios de difusión I y II Boletín del Instituto Andaluz del Patrimonio Histórico, año II, $\mathrm{n}^{0} 7$ y 8 . Sevilla.

Stanley PRice, N.P. (1987) La conservación en excavaciones arqueológicas ICCROM Roma 1984 (Ed. en castellano del Ministerio de Cultura).

Tallón Nieto, M.J. (1997) Pluralidad y disciplina: la arqueología en el marco de un proyecto interdisciplinar Curso: As actuacións no patrimonio construído: un diálogo interdisciplinar. Coordinado por Concha Fontenla San Juan. Xunta de Galicia. Consellería de Cultura.

Teutonico, J.M. (1995) Conservation and management of archaeological sites vol.1, $\mathrm{n}^{\circ} 1$. London.

URTEAGA, M. (1997) La ley del patrimonio cultural vasco: estructura y evolución Col.legi de Doctors i Llicenciats en Filosofí ai Lletres i en Ciencies de Valencia i Castelló. Valencia. 
1. Restos prehistóricos. Jentilarri. Aralar (Guipúzcoa)

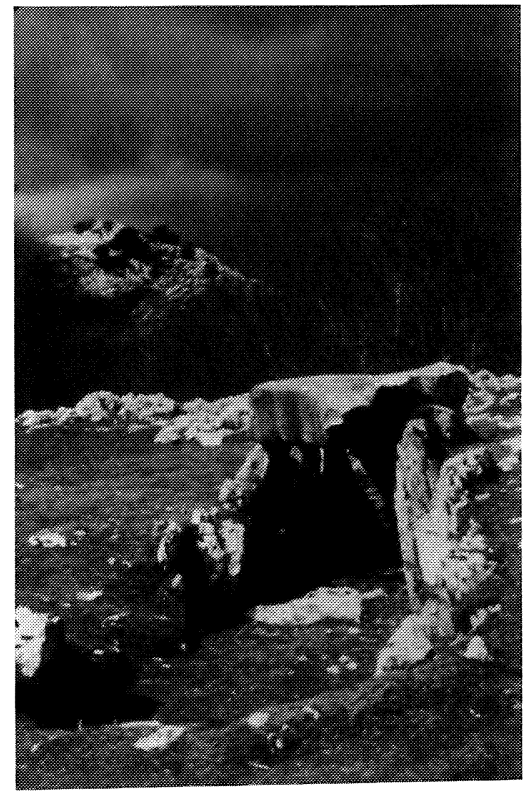

2. Reconstrucción de la escena. Teatro romano de Mérida (Badajoz)

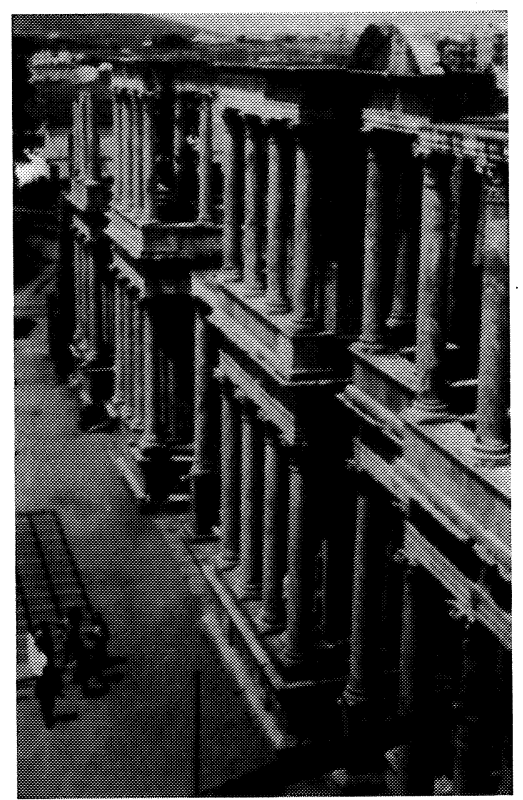




\section{La conservación arqueológica}

3. Sistema de protección. Necrópolis de Puente Noy. Amuñécar (Garanada)

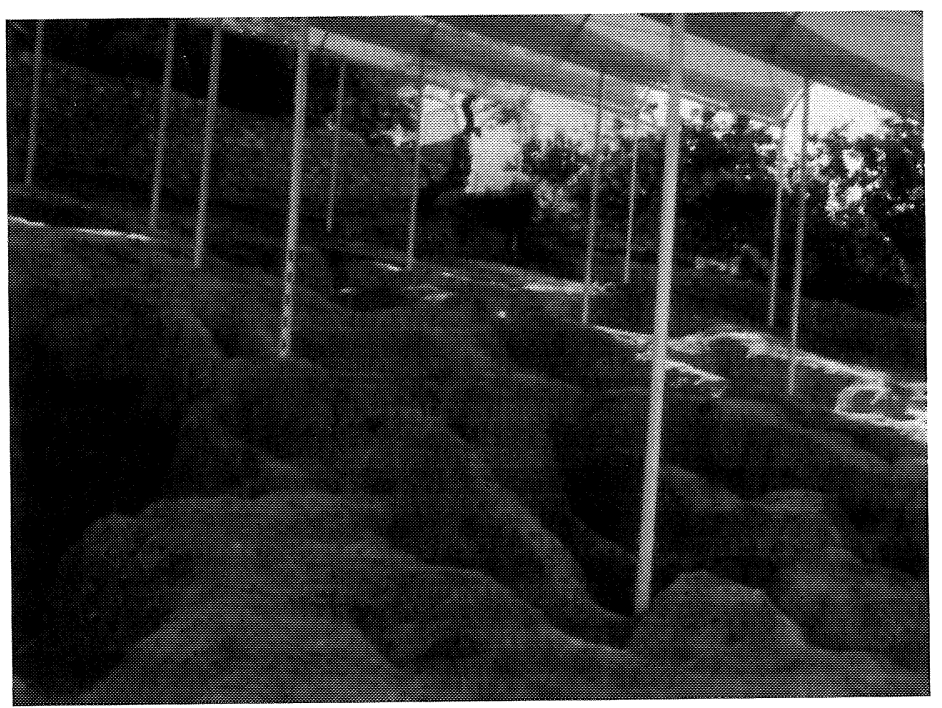

4. Cerramiento en madera. Mosaicos romanos de Valdecarros (Burgos)

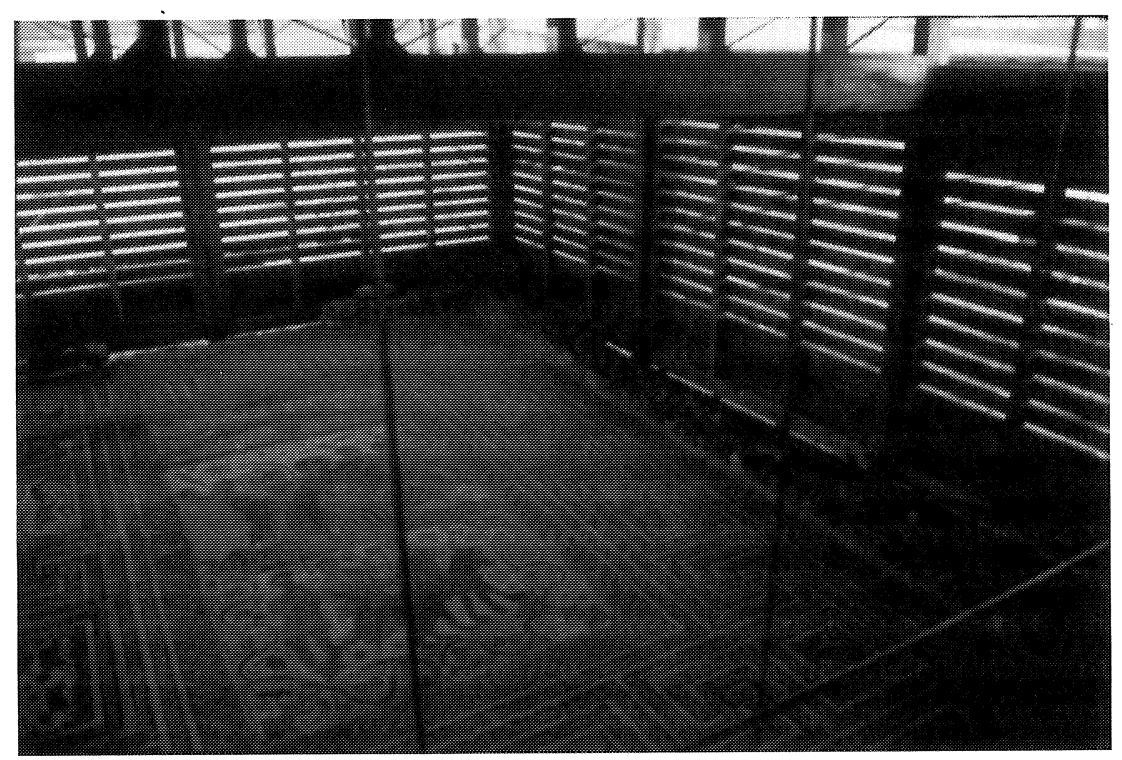

